\section{DEXAMETHASONE SUPPRESSION TEST} DEAR SIR,

The papers of Berger et al (October, 1984) and Mendlewicz et al (October, 1984) raised some important matters regarding biochemical research in depressive disorders. Berger et al (1984) reported a DST sensitivity of $42 \%$ with a "complete lack of specificity" for endogenous depression, while Mendlewicz et al (1984) reported a DST sensitivity of $67 \%$ with a specificity of $100 \%$ for primary major depressive patients.

Mendlewicz et al (1984) used the Schedule for Affective Disorders and Schizophrenia (SADS), the Research Diagnostic Criteria (RDC) and the Hamilton Depression Rating Scale (HDRS). They also applied specific exclusion criteria to avoid false positive DST results. Berger et al (1984) used the ICD-8 (World Health Organisation, 1974) and a selfrating scale for depression.

The selection of a homogeneous group is essential for biochemical research. Both the SADS and the RDC were developed to improve the diagnostic validity and reliability (Spitzer, Endicott and Robins, 1978). The ICD-classification system lacks specific diagnostic criteria, with a low diagnostic validity and reliability (Andreasen, 1982). The DSM III classification system on the other hand has specific diagnostic criteria and is generally seen as an improvement on any existing classification system (Kendell, 1983). Nelson et al (1981) reported a diagnostic accuracy of $77 \%$ with the DSM III for the major depressive episode. To improve the diagnostic validity and reliability Berner $e t$ al (1983) proposed a polydiagnostic approach where different diagnostic criteria are applied to the same patient group. We support this view and suggest that this approach be accepted internationally by researchers - until a better solution is found.

In the study of Berger et al (1984) no statistically significant difference was found between the mood values of the five diagnostic subgroups. This means that the difference (if any) between the endogenous depressed group and the non-depressive neurotic group was not statistically significant. This underlines the importance of specific diagnostic criteria for the selection of homogeneous depressed groups. With the SADS and RDC Mendlewicz et al (1984) were able to select a severely depressed group with a mean value of $35,75 \pm 12,79$ on the Hamilton rating scale for depression.

In our study a polydiagnostic approach was followed to select a homogeneous group of severely depressed patients. These patients met the criteria for primary, unipolar major depressive disorder with melancholia. Patients with a Hamilton depres- sion score below 18 were excluded from the study. Exclusion criteria were used to avoid false positive DST results (Carroll et al, 1981). In support of Mendlewicz et al (1984) we found a sensitivity of $70 \%$ and a specificity of $98 \%$. A significant association was found between a positive DST result and the category major depressive episode with melancholia (DSM III).

\section{A. Gagiano \\ C. AALBERS}

J. J. F. TALJAARD

Research Unit for the Neurochemistry of Mental

Diseases, University of Stellenbosch, Tygerberg, South Africa

\section{References}

American Psychiatric Association (1980) Diagnostic and Statistical Manual of Mental Disorders (DSM III) Washington D.C.

ANDREASON, N. C. (1982) Concepts, diagnoses and classification. In Handbook of Affective Disorders. (ed. E. S. Paykel) Edinburgh: Churchill Livingstone.

Berger, M.. Pirke, K. M., Doerr, P., Krieg, J. C. \& Von ZERSSEN, D. (1984) The limited utility of the dexamethasone suppression test for the diagnostic process in psychiatry. British Journal of Psychiatry, 145, 372-382.

Berner, P., Gabriel, E, Katsching, H., Kieffer W. et al (1983) In Diagnostic Criteria for Schizophrenic and Affective Psychoses. (eds P. Berner, et al) Washington D.C.: American Psychiatric Association.

Carroll, B. J., Feinberg, M., Greden, J. F., Tarika, J. et al (1981) A specific laboratory test for the diagnoses of melancholia. Archives of General Psychiatry, 38, 15-22.

KENDELL, R. E. (1983) DSM III: A major advance in psychiatric nosology. In International Perspectives on DSM III. (eds. R. L. Spitzer, J. B. W. Williams, E. A. Skodol) Washington D.C.: American Psychiatric Press

Mendlewicz, J., Kerkhofs, M., Hoffman, G. \& Linkowski, P. (1984) Dexamethasone suppression test and REM sleep in patients with major depressive disorder. British Journal of Psychiatry, 145, 383-388.

Nelson, J. C., Charney, D. S., Quinlan D. M., (1981) Evaluation of the DSM III criteria for melancholia. Archives of General Psychiatry, 38, 555-559.

SpItzer, R. L., Endicott, J., Robins, E. (1978) Research diagnostic criteria nationale and reliability. Archives of General Psychiatry, 35, 773-782.

DeAR Sir,

\section{KORO}

Recent correspondence (Journal, January 1985, 146, 102-103) and our own experience (Ang \& Weller, Journal, September 1984, 145, 335) suggests a mechanism for Koro. Under states of high anxiety there will be overarousal, with vasoconstrictor sympathetic impulses to the arterioles of the penis. In some people, predisposed by cultural or personal experience, the detumescence may be come a focus for the pre-existing anxiety, thereby creating a vicious circle.

Malcolm P. I. Weller

Friern Hospital, Friern Barnet Road, London N11 3BP 